\title{
Fund proposed to pay for drugs with greater global impact
}

Published at www.cmaj.ca on Feb. 9

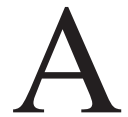
global fund proposed by a Canadian economist would see drug companies rewarded for the health impact of medicines they commit to sell at cost.

The Health Impact Fund, proposed by Aidan Hollis, professor of economics at the University of Calgary in Alberta, and Thomas Pogge, professor of philosophy at Yale University in New Haven, Connecticut, is a pay-forperformance alternative to the pharmaceutical industry's intellectual property rights system.

The fund would give drug companies the option of forgoing monopoly pricing on any new product in exchange for a share of an annual US\$6 billion pool of money (www.yale.edu/macmillan /igh/hif.html).

While participating firms would be required to sell their products at cost, they would still derive profits from annual rewards the fund would pay out over a period of 10 years.

All drugs not being equal, a pharmaceutical innovator's annual cut of the US\$6-billion pool would be based on the demonstrated global health impact of their product, relative to the total assessed impact of all the drugs registered to the fund.

To assess the health impact of a product, the fund would weigh the actual health status of people using the drug with their estimated health status had they not gained access to the drug. The proposed standard measure for this assessment is the quality-adjusted life year, a measure of disease burden commonly used to decide which drugs should be listed in formularies and covered by insurance. In this way, the fund would take into consideration both the quantity and quality of life afforded by a product, aggregating data from whatever sources are available in the market where the drug is released.

After the 10-year reward period ends, drug companies would be

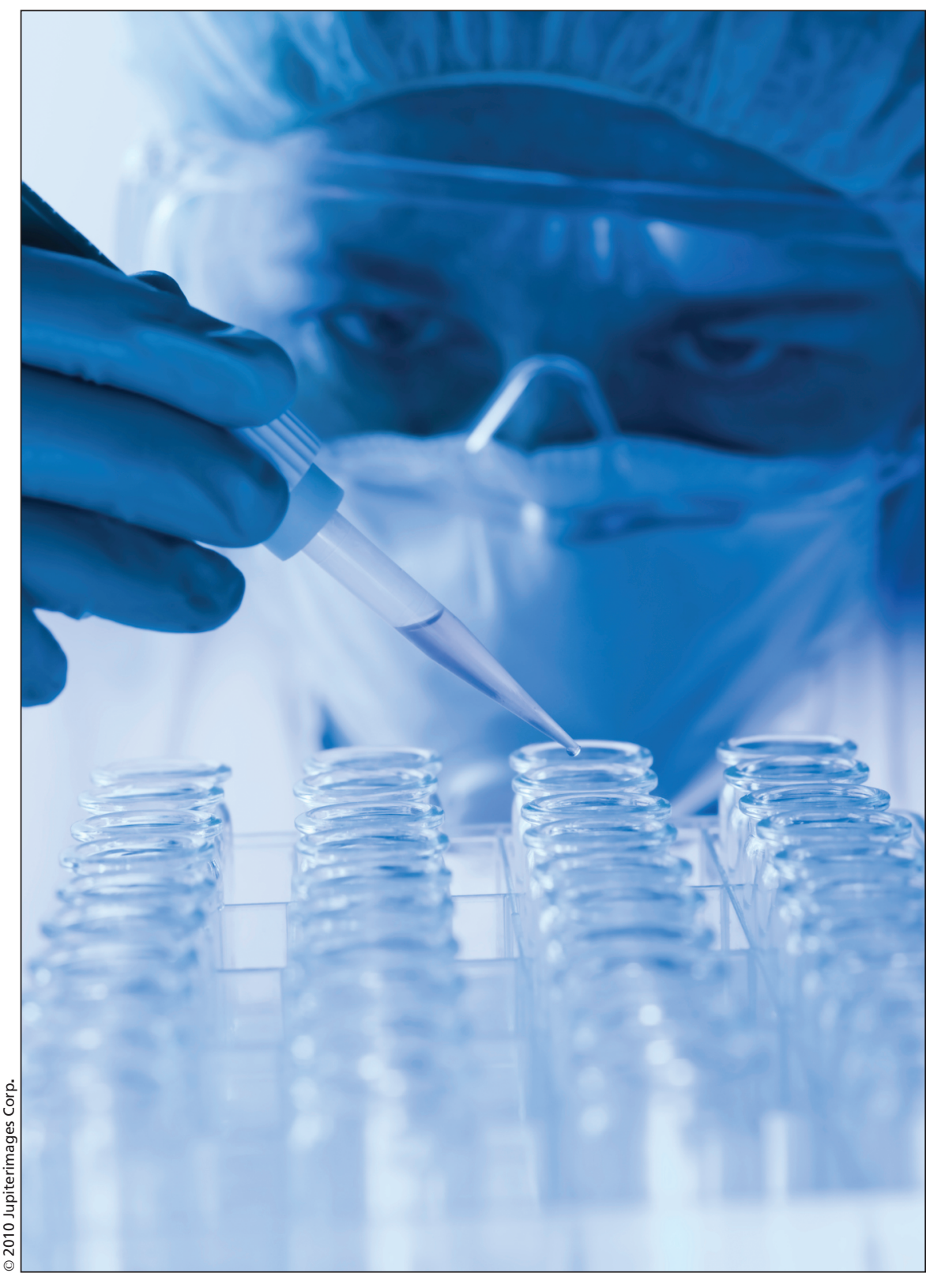

The most profitable medicines that pharmaceutical researchers develop are not necessarily those most needed to ease the global burden of disease.

required to offer zero-price licences for any products registered with the fund, ensuring that generic competition would continue to keep prices low.

"The promise of profit has always been a driving force behind innovation. Why would companies take a risk on a drug that might not sell?" Hollis explains. "The problem we're facing today is that the most profitable medicines to develop are not necessarily those most needed to ease the global burden of disease."

Under the current intellectual property rights system, patentees of new drugs rely on a period of market exclu- 
sivity in which they recoup the costs of innovation as quickly as possible, setting prices at the threshold of what the market will bear.

Drugs that primarily target diseases of the world's poor are unable to make substantial sales at prices necessary to recoup the cost of research and development, says Hollis, so firms rarely bother developing those drugs in the first place.

Protected from generic competition, drugs that make it to market are often priced to maximize profits to a degree that is prohibitive to a large percentage of the world's population, says Hollis, even for people living in developed countries. "There are many solutions that attempt to increase access to medicines by forcing prices down, but it's often done at the cost of making it less attractive for pharmaceutical companies to invest in innovation," he adds. "The idea is not to rip off these companies but to provide them with an alternative way of making money while doing something worthwhile."

The fund would ideally be publicly bankrolled by a number of developed nations and have between 20 and 30 drugs registered at a time.

"Because we're looking for substantial long-term funding commitments, it shouldn't be something that hangs on one or two countries," he says. "We'd need funding for at least 10 years into the future so that firms that are thinking of developing new medicines could be ensured of the money actually being there when they need it."

Pharmaceutical companies holding patents for drugs with a high global health impact but low profitability under the current system stand to gain the most from the fund, says Hollis, but any drug is eligible to be registered.

"By not requiring disease-specific or country-specific solutions, we've left the door open for innovators to come up with whatever they imagine will be most effective for improving global health," he explains. "That means both developed and developing nations can potentially reap the benefits of lower drug prices."

Health economics expert Christopher Longo says that while the Health
Impact Fund is "in concept, a brilliant idea," Hollis overestimates the potential reach of its benefits, particularly to the developed world.

The assistant professor at the DeGroote School of Business at McMaster University in Hamilton, Ontario, has 16 years of industry experience in economic evaluation and market access strategies for pharmaceuticals, and says drug companies' adoption of the fund will always be limited, at best.

"There's little incentive for pharmaceutical companies to register any product to the fund for which an equivalent on the market has set a precedent of higher prices," he explains. "Say a firm was considering registering a diabetes drug that would have applications in both the developed and developing world. Even if there were no other diabetes products that could potentially be cannibalized by releasing the new drug at a low price, the expected sales in the developing world would have to be of a certain magnitude to justify forgoing the chance to maximize profits in the developed countries."

Hollis admits it's still "a little unclear" how much of the fund that will be spent on global diseases should be devoted to neglected diseases. It's a cost of "leaving it all so open."

But Longo suggests that unless the fund puts in place a mechanism to prevent erosion, it's likely to only attract drugs that specifically target neglected diseases and have no equivalents in the developing world market.

"That's by no means a negative outcome from an altruistic perspective," he says. "But if the fund only benefits the developing world, where's the incentive for developed countries to pick up the bill?"

Similarly, University of Toronto pharmacoeconomics expert James Heller calls the proposed fund "admirable but overly idealistic."

"The pharmaceutical companies are still being asked to shoulder all the risk during research and development, and for what? After laying down money for almost 10 years, they have to wait another 10 to see a profit," he says.

He also suggests that the US\$6 billion minimum to be annually distrib- uted by the fund seems "trivial" considering that the rewards will be divided between 20 or 30 products.

Paul Grootendorst, director of clinical, social and administrative pharmacy at the University of Toronto, argues that US\$6 billion is a reasonable starting point, because lump sum rewards don't generate the extra costs associated with selling under the current system.

"Monopoly pricing attracts profit raiders," he said. "If you reward companies in a way that keeps prices low, they can avoid spending on market access specialists, anticounterfeiting controls, and whole lot of litigation."

Grootendorst has studied a number of proposed alternatives to the patent system and says the Health Impact Fund, while imperfect, is the most viable solution on the table, largely because it can happily coexist with the current system.

Tim Gilbert, a patent litigator for the pharmaceutical industry and director of Incentives for Global Health, a multidisciplinary organization of scholars and professionals actively promoting the fund, says organizers are now soliciting critiques of the proposal while it's at a stage where changes can be made.

Gilbert says it's too early to "pop the champagne" on a finished proposal, but notes the Health Impact Fund has already received positive feedback from both public and private groups.

"The World Health Organization's expert advisory committee has earmarked it as one of the leading prospects to incentivize global health and we've received money from both the Australian government and the European parliament towards further investigation of the idea," he says. "I've approached some of my clients and their competitors and it's been exciting to hear that from a very high level a number of drug companies would be interested in seeing this move forward."

Gilbert says their next step will be to lobby the Canadian government to make the Health Impact Fund a topic of discussion at the G20 summit in June. - Lauren Vogel, Ottawa, Ont.

DOI:10.1503/cmaj.109-3172 